The Social Context of Health and Health Work 


\section{The Social Context of Health and Health Work}

Linda J. Jones 


\section{To Charles, and to the memory of Joyce, my mother.}

(C) Linda J. Jones 1994

All rights reserved. No reproduction, copy or transmission of this publication may be made without written permission.

No paragraph of this publication may be reproduced, copied or transmitted save with written permission or in accordance with the provisions of the Copyright, Designs and Patents Act 1988, or under the terms of any licence permitting limited copying issued by the Copyright Licensing Agency, 90 Tottenham Court Road, London W1P 9HE.

Any person who does any unauthorised act in relation to this publication may be liable to criminal prosecution and civil claims for damages.

First published 1994 by

THE MACMILLAN PRESS LTD

Houndmills, Basingstoke, Hampshire RG21 2XS

and London

Companies and representatives

throughout the world

ISBN 978-0-333-55156-1

ISBN 978-1-349-23472-1 (eBook)

DOI 10.1007/978-1-349-23472-1

A catalogue record for this book is available from the British Library 


\section{Contents}

List of figures $\quad$ ix

List of tables $\quad$ xi

List of useful terms xiii

Preface xiv

Acknowledgements xvi

Introduction xviii

1 Health in a social context 1

1.1 Thinking about health 2

1.2 Disease, illness and sickness $\quad 7$

1.3 The influence of official definitions of health 11

1.4 Lay definitions of health $\quad 15$

1.5 The formation of health chances 18

1.6 Research into health inequalities 20

1.7 Investigating personal behaviour 24

1.8 Working for health 29

1.9 Towards a 'social model' of health 32

1.10 The contribution of sociology and social policy 37

2 The scope of sociological enquiry 39

2.1 What is sociology? 40

2.2 Theoretical dilemmas 43

2.3 The sociological tradition: Durkheim, Marx and Weber 50

2.4 The social policy tradition $\quad 58$

2.5 Debates in medical sociology 61

2.6 Social action theories and medical sociology 66

2.7 The problem of gender $\quad 71$

2.8 Social constructionism and medical sociology 74

2.9 The fragmentation of social theory 81

3 The family and health $\quad 85$

3.1 Studying the family 86

3.2 The family in sociology $\quad 87$

3.3 The family and socialisation $\quad 94$

3.4 Social change and the family 98

3.5 The impact of the welfare state on family life 107

3.6 Health work and the family 112

$\begin{array}{ll}3.7 \text { Theories of the family } & 119\end{array}$ 
4 Community and health 128

4.1 The language of community 129

4.2 The 'problem' of community 131

4.3 Community in current sociological debate 135

4.4 Health work and the community 139

4.5 Care in the community 153

4.6 Current policies for community care 161

4.7 Community care and consumer sovereignty 164

4.8 Rethinking community? 167

5 Stratification, class and health 171

5.1 Social stratification 173

5.2 Class as a form of stratification $\quad 175$

5.3 Changing patterns of stratification and inequality $\quad 178$

5.4 Class based inequalities and health status 182

5.5 The debate about class and health 193

5.6 Beyond class? 204

6 Poverty and health in the welfare state 208

6.1 Health and poverty 209

6.2 Defining and measuring poverty 210

6.3 Debates about relative poverty 216

6.4 The welfare state and anti-poverty legislation $\quad 220$

6.5 The current politics of poverty 224

6.6 Poverty and health 229

6.7 Theorising poverty and health 237

6.8 Theories and health work practice $\quad 244$

7 Gender divisions and health 248

7.1 Unpacking sex and gender 249

7.2 Gender and health status 251

7.3 The gendered division of labour 257

7.4 The invisibility of gender in sociological theory 260

7.5 The challenge of feminist analysis 262

7.6 The social construction of caring 271

7.7 Health work as a gendered occupation 275

7.8 Gender and medical practice $\quad 282$

7.7 Gender and nursing 286

8 Race, ethnicity and health 290

8.1 Thinking about ethnicity and race 291

8.2 Theories of race 298

8.3 Investigating the health of black and minority ethnic groups 304

8.4 Black and ethnic minorities and health services 313 
8.5 Equal opportunity and anti-racist strategies in the health sector

8.6 The significance of race in health care

9 Dependency: age and disability

9.1 Unpacking dependency

9.2 The shifting category of the 'disabled person'

9.3 Age and generation

9.4 Theories of old age

9.5 The health of older people

9.6 Health work and dependency

10 Health beliefs and health action 366

10.1 Understanding health and illness 367

10.2 Health belief systems in non-Western societies 371

10.3 The emergence of biomedicine as a belief system 377

10.4 Alternative accounts of health and illness 378

10.5 Lay beliefs about health and illness 385

10.6 Taking action on illness 391

10.7 Illness action and 'sick role' theories 402

10.8 Becoming a patient 405

10.9 Beliefs, action and health work 411

11 Power and control in health work 413

11.1 Pluralism in early health work 414

11.2 The rise of biomedicine 417

11.3 The consolidation of medical power $\quad 426$

11.4 Professional power in health work 429

11.5 Medical control of health work 433

11.6 The health service as an organisation 442

11.7 The search for effective control 450

11.8 Critiques of medical power 452

12 The work of nursing 460

12.1 Nursing as a particular type of work 461

12.2 The social character of nursing 469

12.3 Becoming a nurse $\quad 474$

12.4 The social organisation of nursing work 483

12.5 Health worker-patient interaction 488

12.6 Nursing in the future 501

13 The contemporary politics of health care 504

13.1 The crisis in welfare 505

13.2 The reconstruction of welfare principles 512 
13.3 The crisis in health care 515

13.4 Evaluating market principles in health care 521

13.5 Issues and problems in health care 530

13.6 The future of health and health work 541

List of references 554

Authorindex 579

Subject index $\quad 587$ 


\section{List of figures}

1.1 Expectation of life at birth

1.2 Major causes of death 1931 and 1991

1.3 The health field concept

1.4 Health chances

1.5 Mortality by occupational class and age

2.1 Sociological approaches: a simple model

2.2 Marx's theory of society

2.3 Traditions in social welfare theory

2.4 Parsons' social system

3.1 Live births outside marriage as a percentage of all births

3.2 Infant mortality rates, England and Wales 1846-1982

3.3 Fertility rates, England and Wales 1838-1982

3.4 Women in employment

4.1 NHS expenditure and staffing

4.2 Cost estimates for different types of care

5.1 Unemployment and vacancies 1971-93

5.2 Wealth holding in the UK

5.3 Shareholders as a percentage of the adult population

5.4 Shares held in UK companies by sector

5.5 Disparities between male and female wage levels in the UK

5.6 Social class gradients: selected diseases

6.1 Age-standardised health ratios in men and women aged 40-59 years in relation to weekly income

6.2 Cycle of deprivation

6.3 Cycle of inequality

7.1 Morbidity (reported sickness) rates 1972-92: findings from the General Household Survey

7.2 Key variables associated with women's health status

7.3 Families headed by lone mothers and lone fathers as a percentage of all families with dependent children

7.4 Strategies of occupational closure: a conceptual model

8.1 Percentages of white and black male workers in shift work in the early $1970 \mathrm{~s}$

8.2 Outcome of pregnancy by mother's country of birth: evidence in the 1980s

8.3 Infant mortality and mother's country of birth: evidence in the 1990s 
9.1 Discharges from mental illness and learning disability hospitals and units: stays of five or more years

9.2 The 'social death' model of disability

9.3 The 'social barriers' model of disability

9.4 Dependent population by age

9.5 Age and sex structure of the British population, 1901 and 1981

9.6 Social class gradients in mortality and chronic illness

9.7 Elderly people in residential accommodation

10.1 The Amhara health belief system

10.2 The theory of humors

10.3 The social origins of depression

10.4 Relationships between symptoms and illness behaviour

10.5 An illness action model

10.6 Labelling theory

10.7 'Ideal type' of patient career

11.1 Respiratory tuberculosis: death rates (England and Wales)

11.2 Organisation of the NHS in England and Wales 1948-74

11.3 Organisation of the NHS 1974-82

11.4 Organisation of the NHS 1982-90

11.5 Organisations: a simple model

12.1 Gender order in the Victorian home and hospital

13.1 Mapping traditions in social welfare

13.2 NHS structure post-1990

13.3 Purchaser alliances in the new NHS

13.4 Quality of service evaluation

13.5 Perceived importance of factors contributing to wellbeing and quality of life

13.6 A conceptual model of quality of life 


\section{List of tables}

1.1 Concepts used in the attempt to describe what health is

1.2 The Health of the Nation main targets

1.3 Lay classification of colds and fevers

1.4 Registrar General's classification of occupations

1.5 WHO Health For All targets for Europe, 1985

1.6 Health problems and health work interventions

3.1 Changing family size

3.2 Domestic division of labour

4.1 Community care: main care and accommodation services

4.2 Growth of private sector care

5.1 Britain in the 1840s

5.2 The extension of voting rights (UK)

5.3 British Social Mobility Study: social class model

5.4 Townsend's findings on occupational inequalities

6.1 The extent of poverty in Britain 1960-1987

6.2 The risk of poverty for the various population groups in Britain in the 1980s

6.3 Indicators of deprivation

6.4 Shifting views of poverty

6.5 Distribution of disposable household income

6.6 Keeping the family on low-cost budgets

6.7 Health education approaches

7.1 Selected causes of death: by sex and age, 1992

7.2 Standardised mortality ratios for women and men by marital status

7.3 'Normal' and 'deviant' women

7.4 Hospitalisation of childbirth

8.1 UK migration patterns since the 1940s

8.2 Unemployment rates by ethnic group, Spring 1993

8.3 Reported cases of racial harrassment in London 1979-93

8.4 Summary of main findings of Immigrant Mortality Study

8.5 Asian callers' reasons for phoning the counselling service

8.6 NAHA guiding principles and objectives

9.1 Main targeted benefits for long term sick, injured and disabled people

9.2 Inability to undertake mobility, self care and domestic tasks

9.3 Housing tenure and health status

10.1 Concepts in conventional and alternative medicine

10.2 Culture and symptoms 
10.3 Parsons' 'sick role' theory: a summary

10.4 Open and closed institutions

11.1 Changing modes of production of medical knowledge

11.2 National Health Service expenditure UK 1949-88

11.3 Analysis of NHS general managers: by background

12.1 Model of nurse socialisation

12.2 Perceived advantages and disadvantages of supernumerary status

12.3 Nursing and midwifery staff: by sex and specialty, 1989

12.4 Four types of nurse-patient relationship

13.1 Social expenditure in relation to UK government expenditure 1981-92

13.2 The rise of managerialism

13.3 Classification of states of illness

13.4 Valuation matrix

13.5 Performance indicators 


\section{List of useful terms}

Standard mortality (death) rate - deaths per 1000 of the population, standardised for age

Standardised mortality ratio (SMR) - compares the standard mortality rate for the whole population with that of a particular region, group and so on, expressing this as a ratio

Potential years of life lost (PYLL) - compares life expectancy of the whole population with that of particular groups, regions and so on, expressing this as a ratio

Infant mortality rate (IMR) - deaths at all ages under one year (per 1000 live births)

Perinatal mortality rate $(P M R)$ - stillbirths and deaths in the first week of life (per 1000 total births)

Neonatal mortality rate (NMR) - deaths in the first 28 days of life (per 1000 live births)

Maternal mortality rate (MMR) - deaths per 100000 women in the population from complications of pregnancy, childbirth of puerperium

Stillbirths - foetal deaths after 28 completed weeks of gestation 


\section{Preface}

Many people have contributed to the realisation of this project, not least the health studies students and pre-registration nurses, midwives, health visitors and district nurses I have taught over the years. In particular, the pilot Project 2000 Diploma students of South Birmingham Health Authority in the later 1980s forced me to confront the problems of teaching health sociology and policy perspectives on health work courses. Students on the part-time nursing degree helped me to respond to this challenge and to demonstrate the practical value of social theory and research for health work.

Thanks are also due to the nurse tutors and to lecturers at the (then) Birmingham Polytechnic. In particular, Roswyn Brown, Course Director of the part-time nursing degree, gave me support at a critical time to develop the part-time sociology programme for nurses. Judy Hubbard, Course Director of the health studies degree, a physiologist and a longstanding friend and colleague, stimulated and challenged my thinking about health.

Colleagues in the Department of Sociology and Applied Social Studies gave me much sound advice and valued support over the years. In particular, I want to record my thanks to Peter Tetley, who introduced me to Michel Foucault's work, to Bob Kornreich, with whom I taught a sociology of health elective and from whom I learned a great deal, and to George Smith, for his wide knowledge and uncompromising defence of social policy.

My Open University colleagues have been generous to a fault. In spite of their own pressing deadlines Moyra Sidell and Stephen Pattison have read and commented on various drafts and have done their best to improve them. To Alan Beattie and Moyra Sidell, my fellow course team members on K258 Health and Wellbeing, I owe a tremendous debt. Working with them on the making of this course enabled me to review and relocate nursing within the broader context of formal and informal health work and to appreciate more clearly the significance of lay and alternative beliefs about health.

Graham Moon at Portsmouth and Margaret Miers and her colleagues at Bristol gave me detailed comments and constructive advice on every chapter, and undoubtedly improved the focus and flow of the text. Petra Kopp, my copy editor, has remained consistently cheerful and helpful, even when asked to do the near impossible. The book is much easier to read as a result of her efforts. 
Finally, my love and thanks are due to Charles, Kate and Ellen for putting up with my tiredness and bad temper and for supporting and encouraging me when the writing was going badly and the deadlines were uncomfortably close. Without their help this book would never have been completed. Needless to say, the remaining mistakes and oddities, and the views expressed, are entirely my own responsibility. 


\section{Acknowledgements}

The author and publisher would like to thank the following for permission to use copyright material:

The Controller of Her Majesty's Stationery Office for figures, extracts and tables from Social Trends (1993 and 1994), from OPCS (1994) General Household Survey, 1992. Series GHS No. 23, OPCS Longitudinal Study (1982), Perinatal and infant mortality statistics (1990), Working for Patients (1989), The Health of the Nation (1992); Kluwer Academic Publishers for a table from C. Helman (1978) 'Feed a cold: starve a fever' in Culture, Medicine and Psychiatry 2; Edward Elgar Ltd for tables from V. George and I. Howards (1991) Poverty Amidst Affluence; Elsevier Science Ltd, The Boulevard, Langford Lane, Kidlington OX5 1GB, UK for a table from C. Aakster (1986) 'Concepts in alternative medicine' in Social Science and Medicine, Vol. 22, No. 2; The Open University for figures and tables from K258 Health and Wellbeing and from K205 Health and Disease; Berg Publishers for a figure from A. Young (1986) 'Internalising and externalising medical belief systems' in C. Currer and M. Stacey (eds) Concepts of Health, Illness and Disease; Policy Studies Institute Publications for figures from J. Percy-Smith and I. Sanderson (1992) Understanding Local Needs; Churchill Livingstone for a figure from J. Bond and S. Bond (1986) Sociology and Health Care; Routledge Ltd. for a figure from A. Witz (1992) Professions and Patriarchy; Sage Publications Ltd for a figure from B. Hughes (1990) 'Quality of life' in S. Peace (ed) Researching Social Gerontology; Oxford University Press for a table from J.H. Goldthorpe et al. (1980) Social Ability and Class Structure in Modern Britain; The Macmillan Press Ltd for tables from C. Ham (1992) Health Policy in Britain (3rd edn) and a case study from E. Anionwu (1993) 'Genetics - a philosophy of perfection?', in A. Beattie et al. (eds) Health and Wellbeing: A Reader; NAHAT (National Association of Health Authorites and Trusts) for a table and figure from Purchasing for a Healthy Population (1993), and for tables from The Health Service Yearbook (1993) and Action, Not Words (1988); Blackwell Scientific Publications for a figure from J. Morse (1991) 'Negotiating commitment and involvement in the nursepatient relationship', Journal of Advanced Nursing, 16, pp. 455-7; Tavistock/Routledge for figures for M. Blaxter (1990) Health and Lifestyles, M. Jeffreys et al (eds) Growing Older in the Twentieth Century and G. Brown and T. Harris (1978) Social Origins of Depression; Wigmore Publications Ltd. for an extract from Homeopathy for the Family (1988) 8th 
edn.; Hodder and Stoughton for an extract from A. Brechin and J. Walmsley (1990) Making Connections; the National Extension College for material from Health Care in Multiracial Britain (1985); Open University Press for a table from C. R. Victor (1991) Health and Health Care in Later Life and a figure from M. Loney et al (eds) (1983) Social Policy and Social Welfare; Taylor and Francis for a figure from P. Abbott and G. Payne (eds) (1991) New Directions in the Sociology of Health; Equal Opportunities Commission for figures from Men and Women in Britain 1993.

Every effort has been made to trace all copyright holders, but if any have been inadvertently overlooked the publisher will be pleased to make the necessary arrangements at the first opportunity. 


\section{Introduction}

Two main types of experience have helped to shape this book: face-toface teaching work with nurses and other health students, and developing distance learning materials at the Open University. When the book was first planned it was to be a short text for nurses, harnessing the practical experience of planning and delivering health sociology and policy on a Project 2000 pilot course. So much has happened since then - to nurse education, to health care organisation and to health and welfare in general (as well as to the author) - that the finished book is rather more ambitious: larger, more reflective, more broadly based in health studies and more challenging to students.

Some students will always want a straightforward 'sociology textbook', and for them this book outlines key sociological concepts and theories and applies them to health work. But it also breaks new ground by linking together sociology of health and social policy perspectives, in the belief that students need both to reflect on the nature and meaning of their own practice and to tease out the relationships between social theories and health and welfare policies.

It is clear that the health sector is being transformed by market pressures and neo-liberal ideologies. Nurses and other health workers face new challenges from rapid changes in established training and work patterns. Primary and community care are growing and the hospital workforce is shrinking. Patients' charters, health targets, contracts and skill mix are the buzz words of the 1990s. At the same time relative poverty, health inequality and unequal opportunities are marked features of contemporary Britain. Demand for health care is growing, but so too are disenchantment with modern medicine and interest in alternative therapies.

The book seeks to explain why inequalities persist, why health work is in such a state of flux and why conflicts over welfare are growing. It does so not by narrowly focusing on health care but by encouraging students to understand how they themselves, as well as their patients and clients, are positioned within a broader social context. Debates about health policies are linked to wider conflicts over welfare. Trends in health and disease are explored in relation to contemporary social divisions of class, race, gender, age and disability. Changing practices and relationships in health work are also related to these broader patterns of social change.

Chapter 1 sets health in a social context, exploring how concepts of 
health, illness, disease and sickness have been shaped by lay beliefs and expert discourse. It introduces central themes in the book: the complexity and shifting basis of health itself, the scope and significance of inequalities in health, and possible uses of the 'social model of health' in contemporary health work.

Chapter 2 outlines major perspectives and theories in sociology and social policy which have influenced our thinking about health and health work. It introduces the main perspectives in social policy, in particular the influence of Fabianism and of the New Right in the 1980s. It briefly explores how the ideas of Marx, Weber and Durkheim have influenced current thinking about health and illness, reassesses the contribution of Talcott Parsons and outlines the work of social action and feminist theorists. The rise of social constructionism in medical sociology is set within a wider framework of postmodernist thought.

Chapters 3 and 4 focus on the family and on community, institutions which have become the focus of intense social and political pressure. Chapter 3 explores the changing structure and character of the family, relating this to broader economic and social change and reflecting on the implications for health work practice. It outlines the growth of state welfare provision for the family and the main structures of the welfare state. Chapter 4 examines the concept of 'community' and explores the scope and character of community health work, in particular the growth of community care.

Chapters 5-9 explore various dimensions of power and inequality in contemporary society. Theoretical insights from sociology and social policy are used to illuminate current features of health work organisation and practice. Class, race, gender, age and disability are examined both in terms of their relationship to health status and their impact on health work. Chapter 6 investigates why poverty persists in the affluent UK and why it has had such a profound impact on health.

Chapter 10 develops the analysis of health beliefs and health action begun in Chapter 1 . It notes the wide range of offical ideas about health, from non-Western as well as Western cultures. Theories of health behaviour are reviewed and the role of the 'patient' within different health work systems is assessed.

The final three chapers explore in greater detail various aspects of health care organisation and delivery. Chapter 11 looks at power and control in health work, charting the rise to dominance of the medical profession and its influence over the division of labour in health care. Together with Chapter 13, it considers the establishment and growth of the National Health Service and changes in its structure and organisation.

Chapter 12 discusses the work of nursing, drawing on the analysis of class, race and gender offered in earlier chapters. Nursing is explored 
as a complex and ever-changing activity, influenced by both a medical and a social model of health, by new ideas about holism and empowerment and by changes in nurse education and training.

Chapter 13 reviews the contemporary politics of health care, the rise of managerialism, of contractualism and of the purchaser-provider split in health. The book concludes by reviewing prospects for health and health work in the future: for promoting health rather than treating disease, for broader evaluation of health care interventions, for increasing user participation and for the reformulation of health work itself.

\section{How to use this book}

The range of material in this book means that it can be used in several ways. Some students will choose to work through it chapter by chapter; others will dip into the book for particular purposes, to learn more about poverty and health, sociological theories or contemporary health policies. Those who have a grounding in sociology and social policy should find Chapter 2 a useful summary of perspectives and theories. Those who are coming new to these fields may find it more helpful to read Chapter 2 after having studied some of the other early chapters, such as those on the family and community.

However you use the book you will find help and guidance in every chapter. They all have summaries of major themes and issues at the start, together with learning outcomes so that you can check your progress through the text. Within each chapter there are comments, questions and ideas to set you thinking about what you are reading. You can, of course, ignore these and read on - the 'answers' are always provided for you - but the hope is that you will become an 'active reader' who reviews and evaluates the material presented. At the end of each chapter there are self assessment questions to enable you to check your understanding of the text. Frequent cross-references help you to review earlier sections of the book, and separate subject and author indexes enable you to track down ideas and references.

However you choose to use this book, I hope you find it as enjoyable and valuable to read as I found it stimulating and challenging to write. 